\title{
ÁREAS VERDES NA CIDADE DE CAMBÉ-PR
}

\section{Green areas in the city of Cambé-PR}

\author{
Carlos Cassiano Dalto \\ Discente do curso de graduação em Geografia da Universidade Estadual de Londrina \\ carlos.cassiano1@uel.br
}

Giovani Delafronte Discente do curso de graduação em Geografia da Universidade Estadual de Londrina g delafronte@outlook.com

Heloísa Maria Montavan Discente do curso de graduação em Geografia da Universidade Estadual de Londrina heloisamariamantovani@hotmail.com

Edinéia Vilanova Grizio-Orita
Docente da Universidade Estadual de Londrina (UEL) - Departamento de Geociências
edineia@uel.br

RESUMO: Esta pesquisa foi desenvolvida na área urbana da cidade de Cambé/PR, com o objetivo de discutir a importância da conservação das áreas verdes e a sua relação entre homem e natureza com a qualidade de vida ao utilizar-se de ribeirões, rios e áreas verdes urbanas e rurais do município. Há necessidade de se discutir alternativas de sustentabilidade ecológica que minimizem a degradação ambiental, não apenas para a área de estudo, mas para todas as cidades que tenham concentrações populacionais que causam danos ao meio ambiente. É possível perceber que com a responsabilidade socio/ambiental e a conexão homem - natureza podem ser os caminhos para a conservação ambiental e suas funções indispensáveis na estruturação de uma cidade moderna. Desta forma, foi utilizada como metodologia a pesquisa em literaturas diversificadas e investigação de fenômeno geográfico in loco. Conclui-se que desde a década de 1990, foram construídos 04 novos bairros as margens do ribeirão Barra Grande além de uma subestação de tratamento de esgoto e que neste local passou por grandes transformações na perda de sua vegetação natural, aumento na erosão do solo e com diminuição da vazão de águas ao longo do seu leito. Hoje a cidade possui 14 praças (Amigos da Praça) e/ou rotatórias que foram revitalizadas com árvores e flores, em conjunto com a iniciativa privada local.

Palavras-chave: Educação Ambiental; Conservação; Ambientes Urbanos; Qualidade de Vida.

ABSTRACT: This research was developed in the urban area of the city of Cambé/PR, whit the objective to discuss the importance of the conservation of the green areas and its relationship between man and nature with the quality of life when using riversides, rivers and urban and rural green areas in the county. There is a need to discuss ecological sustainability alternatives that minimize environmental degradation not only for all cities that have population concentrations that cause damage to the environment. It is possible to perceive that with the social / environmental 
responsibility and the connection man - nature can be the paths for the environmental conservation and its indispensable functions in the structuring of a modern city. In this way, it was used as methodology the research in diversified literature and investigation of geographic phenomenon in loco. It is concluded that since the 1990s, 04 new neighborhoods have been built on the banks of the Barra Grande stream, in addition to a sewage treatment substation, which has undergone major transformations in the loss of its natural vegetation, increased soil erosion and with decreasing water flow along its bed. Today the city has 14 squares (Amigos da Praça) and / or roundabouts that have been revitalized with trees and flowers, together with the local private initiative.

Keywords: Environmental education; Conservation; Urban Environments; Quality of life.

\section{INTRODUÇÃO}

Com as crescentes pressões humanas nos ambientes naturais, a Educação Ambiental torna-se cada vez mais importante e apresenta-se como um meio de buscar apoio e participação dos diversos segmentos da sociedade para a conservação e a melhoria da qualidade de vida. A Educação Ambiental propicia o aumento de conhecimentos, mudanças de valores e o aperfeiçoamento de habilidades, que são condições básicas para que o ser humano assuma atitudes e comportamentos que estejam em harmonia com o meio ambiente (PADUA e TABANEZ, 1997).

A questão das áreas verdes urbanas possui sua importância no sentido de valorizar seu papel funcional no metabolismo da cidade, ou seja, as áreas verdes atuam no conjunto dos fenômenos químicos e físicos mediante os quais se faz a assimilação das substâncias necessárias à vida (FEIBER, 2004). Atualmente, as intervenções antrópicas no meio ambiente natural estão sendo vistas como a maneira de se conservar e manter, reconstruindo e transformando, de maneira a reencontrar o equilíbrio entre a natureza e o ambiente urbano. Ainda de acordo com a autora, a cultura local e o modo de produção da cidade, este se constitui o maior agente causador de impactos sobre a natureza.

Entende-se que as áreas verdes são classificadas e qualificadas em duas categorias: áreas verdes de recreio e lazer e áreas verdes de proteção e enquadramento. As primeiras correspondem a jardins e parques urbanos de maior dimensão existentes ou áreas que potencialmente venham a adquirir estas características. As áreas verdes de proteção e enquadramento são aquelas que visam à salvaguarda de valores naturais, proteção dos ecossistemas, habitats, povoamentos ou formações vegetais e valor ecológico e ou didático, ou ainda as estruturas vegetais que protegem o solo em relevo declivoso com tendências de erosão ou vegetação de proteção das infraestruturas viárias (QUEIROZ, 2018).

As áreas verdes são fundamentais para a conservação da qualidade ambiental das cidades, já que assumem um papel de equilíbrio entre o espaço modificado para o assentamento urbano, e o meio ambiente. Notadamente, percebe-se esta importância diante de um local com redução ou até mesmo ausência de arborização: desconforto térmico e possíveis alterações no microclima são algumas variáveis ambientais identificadas. Mas além dessas, a falta desses espaços interfere na qualidade de vida da população, já que essas áreas assumem um papel de lazer e recreação.

Este trabalho objetivou analisar a importância de algumas áreas verdes no município de Cambé-PR, com a necessidade de conservação e/ou recuperação. Desta forma, esta pesquisa teve como finalidade auxiliar a conscientização social, no que diz 
respeito às contribuições das áreas verdes dentro do perímetro rural e urbano para minimizar os problemas ambientais relacionados à expansão urbana em áreas verdes como também demostrar a relevância da relação de convivência do homem e natureza.

\section{MATERIAIS E MÉTODOS}

Para a realização desta pesquisa foi utilizado o método de caráter qualitativo, e desenvolvida a partir da metodologia de trabalho de campo, que se caracteriza pela investigação de fenômeno geográfico in loco, além da revisão bibliográfica e análise documental em jornais regionais, incorporada nesta pesquisa para ampliar o âmbito de dados e para demonstrar o número de eventos e seus principais impactos causados na cidade.

Os jornais são fontes relevantes para aquisição e entendimento de eventos diversos (SILVA et al., 2012; CALDANA, 2018) e podem servir para informar sobre os danos sociais, sanitárias, econômicos e/ou ambientais. Na utilização desta metodologia buscou-se descrever as condições locais por meio da observação de registros fotográficos e anotações. Primeiramente, buscou-se conhecer as localizações das áreas verdes e na sequência apresentou possíveis roteiros para as visitas como meio de conhecer e relacionar o homem com a natureza.

\section{ÁREA DE ESTUDO}

A cidade de Cambé-PR (Figura 1), situa-se na porção Norte do Estado do Paraná, com uma área territorial de $494,37 \mathrm{~km}^{2}$, com uma população estimada de 108.126 habitantes (IBGE, 2021) dos quais $96,1 \%$ residem na área urbana e com uma densidade demográfica de 195,47 hab/ $\mathrm{km}^{2}$ (IBGE, 2010).

Em relação ao relevo, Cambé está situado no $3^{\circ}$ Planalto Paranaense que possui altitudes que variam entre 550 e 820 metros. O município está assentado num espigão, cujo ponto mais alto atinge 670 metros de altitude com relevo suavemente ondulado. Já a sua hidrografia está localizada na área da Bacia do rio Paranapanema, cujo principal afluente é o rio Tibagi (NOGUEIRA, 2008).

Os principais Ribeirões são: Couro de Boi, Jacutinga, Três Bocas, Cafezal, Cambé, Barra Grande e Vermelho. Cambé também possui 02 parques municipais o Parque Municipal Peroba Ana Rosa e o Parque Municipal Danziger (PLANO DIRETOR MUNICIPAL DE CAMBÉ, 2017). As áreas rurais estudadas foram o ribeirão Barra Grande, os parques municipais Peroba Ana Rosa e Danziger. Já as áreas urbanas foram o parque municipal Zezão, as praças Sol Nascente e Getúlio Vargas, além das rotatórias no centro da cidade. 


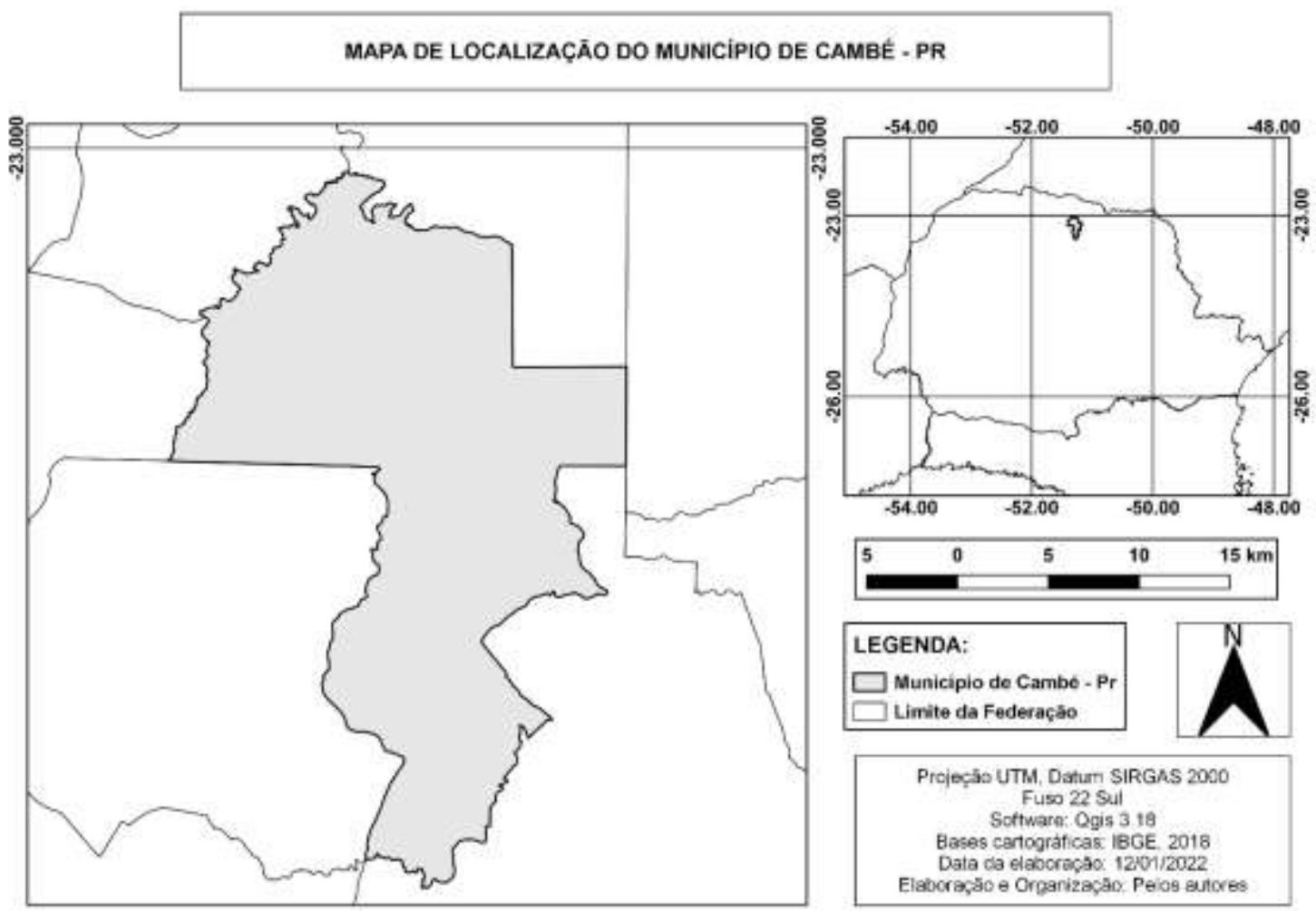

Figura 1. Localização de Cambé/PR. Fonte: IBGE (2019). Adaptado pelos autores, 2020.

O municipio de Cambé, originou-se a partir de 1925, pela Companhia de Terras Norte do Paraná que adquiriu uma área de 515 mil alqueires de matas nativas, equivalentes a $14 \%$ do total do Estado do Paraná, de solo fértil e pronta para ser colonizada. A princípio Cambé foi chamada de Nova Dantzig, que eram os alemães oriundos da cidade de Dantzig atual Gdansk, na Polônia, tornada independente após a $1^{\text {a }}$ Guerra Mundial (IBGE, 2022).

As primeiras 10 famílias chegaram à futura colônia de Nova Dantzig em janeiro de 1932. Durante esta década Nova Dantzig foi elevado à categoria de Distrito Judiciário no munícpio de Londrina-PR. Já na decada de 1940, pela Lei 2, de 11 de outubro de 1947, Nova Dantzig passou a se chamar Cambé, nome de um Ribeirão que banha o município (CAMBÉ, 2021).

No início da colonização, além da extração da madeira muito abundante em toda região, o café, algodão, cereais e a criação de animais faziam parte da cultura diversificada de Cambé, pois o sistema de pequenas e médias propriedades rurais planejados pela Companhia de Terras estimulava a atividade econômica voltada para a terra (IBGE, 2022).

Segundo a classificação de Köppen, o clima de Cambé é classificado como Subtropical Úmido - Cfa (IAPAR,2020). Já Carta de Divisão Climática do Paraná (IAPAR, 2020), organizada para a Região Metropolitana de Londrina, mostra que, além do $\mathrm{Cfa}$, Cambé apresenta quadros de interferência do tipo Cwa, clima subtropical de inverno seco e uma altitude de 670 metros. O seu Bioma predominante é de Mata Atlântica além de apresentar áreas de matas nativas, remanescentes e Matas Pluviais Tropical de Planalto (IBGE, 2010). 
Segundo a classificação do IBGE, a área do Município de Cambé está inserida na região da Floresta, e próximo aos rios, apresentando também influência da floresta, com composição floristica de gêneros como: exemplos: Parapiptadenia rígida (Gurucaia), Cedrella físsilis (Cedro Rosa), Araucária angustifólia (Araucária), Luehea devaricata (Açoite-cavalo), Campomanesta xanhocarpa (Guabirova), Cabralea canjerana (Canjerana), Cassia leptophylla (Canafistula), Talebuia alba (Ipê-amarelo), Ocotea cf.acutifolia (Canetão), Patagonula americana (Guajuvira), entre outras (NOGUEIRA, 2008).

\section{RESULTADOS E DISCUSSÕES}

As primeiras ideias quando pensamos em áreas verdes é sobre a sua utilidade e a sua preservação com a sua totalidade dimensão (CAVALHEIRO; DEL PICCHIA, 1992; LONDE; MENDES, 2014). Os órgãos de planejamento municipais e do meio ambiente utilizam para categorizar a vegetação presente nos municípios em termos das áreas verdes, os espaços e/ou áreas livres, a arborização urbana, o verde urbano e a cobertura vegetal têm tido como os termos utilizados em suas definições (SANTOS; FLORES; ZANIN, 2012).

Porém, estes termos devem ser analisados como expressões e jamais descrevem os mesmos componentes (LIMA et al., 1994). A falta de concordância nestes termos é uma possível causa de ligação da vegetação ao ser tratada sobre várias formas e perspectivas, entre vastas áreas de conhecimentos diferentes e nos órgãos públicos que são os encarregados pela a vegetação urbana. Esta falta de entendimento acaba gerando conflitos na análise da vegetação que estão presentes nas cidades, o que prejudica a análise entre as pesquisas que são praticadas (COSTA; COLESANTI, 2011), assim hoje tem gerado consequências na qual se refere à disseminação desses conhecimentos no ensino, no planejamento e na administração dos territórios verdes (GUZZO, 1999; LONDE; MENDES, 2014).

A autoridade do município, a organização e a administração dos territórios verdes estão previstos no plano diretor e são determinadas seguindo os critérios de progresso e da ampliação das áreas urbanas. Desta forma, nestes planos, a extensão do termo tem como característica a área que se relata ao espaço onde se tem as áreas verdes com vegetação, que estão as praças, os jardins, os locais de conservação, os canteiros centrais de ruas, as avenidas, os trevos e as rotatórias em vias públicas.

Apesar da característica da condição ambiental urbana existir em leis e na academia (BUCCHERI-FILHO; TONETTI, 2011), não é muito utilizada nos atos no seu progresso ambiental nos territórios do citadino, isto é, nos espaços verdes públicos urbanos. Estes territórios, sendo constituídos em lugares que prevalecem a vegetação arbórea, trazem vários proveitos que auxiliam na qualidade ambiental em localizações de grandes construções verticais e horizontais, como diminuição da sensação termina provocada pelas as edificações, a melhoria da impureza do ar, a poluição sonora e a visual, além de um acolhimento para o ecossistema (NUCCl, 2008).

Ainda de acordo com o autor, é essencial que a área urbana, aja como anunciador da qualidade de vida ao encontrar a sua identidade ao lazer e a recriação das pessoas que ali moram, e assim caracterizar em regiões de convivência das 
pessoas e das mais variadas expressões da comunidade que ali vive ou que visita. Assim, as demonstrações da qualidade ambiental nos municípios estão mais óbvias, pois os locais urbanos são caracterizados por apresentarem os maiores problemas ambientais, tais como poluição de água e ar, deslizamentos de encostas, aumento da população pelos carros e indústrias além do intenso uso do solo na malha urbana (LOMBARDO, 1985; LONDE; MENDES, 2014).

Uma das formas de diminuir essas questões citadas é que os territórios verdes estão se tornando um debate dos estudos em diferentes comunidades acadêmica (MAZZEl et al., 2007) sobre as diversas áreas. Assim os saberes estão investigando como as vantagens que trazem para a população sobre os territórios verdes para a saúde e o bem-estar das pessoas, iniciando pelas ideias de que os territórios, ao se evoluir pelas as suas utilidades ecológicas, sociais e lazer conseguem ajudar de maneira eficaz a capacidade de toda a área ambiental e das pessoas que moram e visita essas localidades.

Segundo Kamp et al., (2003) existe uma diferença entre as áreas ambientais e a qualidade de vida, ao se posicionar o primeiro termo como se fosse uma completação do segundo. Assim, a qualidade de vida surge como um termo maior, pois envolve dentre os variados elementos os aspectos socioeconômicos, culturais e ambientais. Estudo realizado por Buccheri-Filho; Tonetti (2011), na temática da habilidade ambiental nas paisagens urbanas, os autores descrevem que a qualidade ambiental urbana enquanto componente da qualidade de vida, é capaz de ser descrita como uma amplitude de situações favoráveis de meio urbano, que podem suprir as carências fisiológicas e psicológicas do ser humano, e o efeito disso seria o avanço do padrão de vida das pessoas.

O município de Cambé (Figura 2) situa-se no bioma brasileiro da Mata Atlântica (IBGE, 2019), foi verificado que hoje sua cobertura original encontra-se em diferentes estágios de regeneração. Conforme o Plano Diretor de Desenvolvimento de Cambé (2017) estima-se que apenas 3\% do território é coberto com matas. Quatro áreas são destacáveis como remanescentes de florestas, todas situadas a norte da área urbana, em área rural: Mata da Fazenda Santa Dalmácia, Mata Fazenda Ibicatu, Mata Dr. Paulo, e Mata Fazenda Dr. Iverson. 


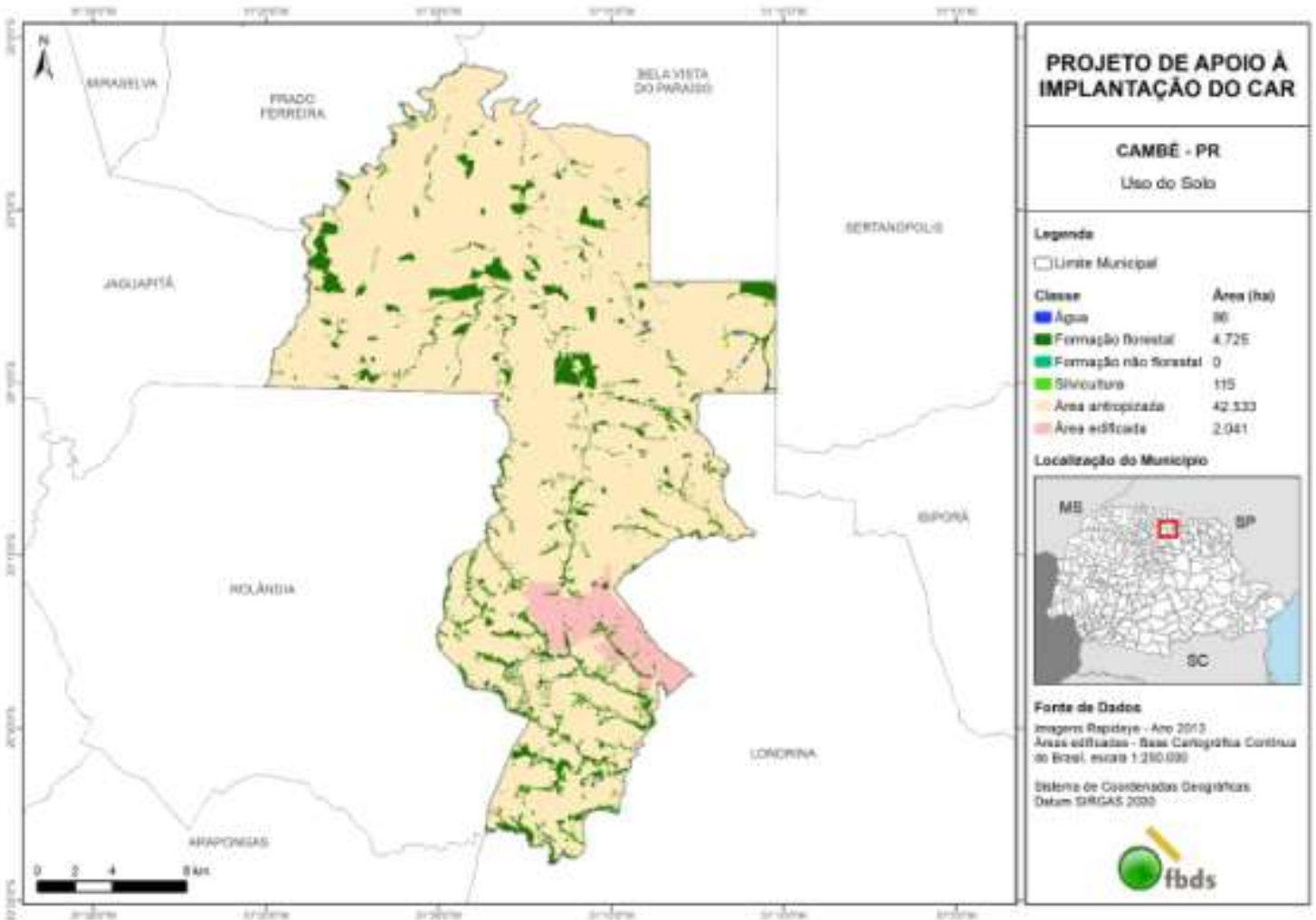

Figura 2. Uso do solo da cidade de Cambé -PR. Fonte: Projeto de Apoio à Implantação do CAR.

O município está localizado na área da Bacia do rio Paranapanema, cujo principal afluente de Cambé é o rio Tibagi. Do rio Tibagi são tributários três rios, cujas nascentes estão localizadas em áreas urbanas de Cambé: Ribeirão, Jacutinga, ribeirão Cafezal e ribeirão Três Bocas. O ribeirão Vermelho que tem nascentes em Rolândia e segue em direção da região norte do Município, é afluente do rio Paranaense e recebe as águas dos rios Barra Grande e Caçadores que tem cabeceiras também na área urbana de Cambé. O Município tem ainda os ribeirões Verdes, Cambézinho, Esperança, Glória, dos Porcos, Lins, Mimoso (NOGUEIRA, 2008).

A cidade de Cambé possui dois parques (Figura 3) o Parque Histórico Municipal "Danziger Hof", que é parte da colônia Neo Danzig, núcleo de imigrantes alemães da cidade de Danzig. Neste parque é situada a casa da família Tkotz, construída no início da colonização, que foi adquirida pela prefeitura da cidade em 2000 e transportada para o parque histórico, onde nela hoje são realizadas atividades culturais. Outra casa também presente é a casa da família Zifchak, sede do parque, que também foi adquirida pela prefeitura e transportada ao parque histórico (Prefeitura Municipal de Cambé, 2020). 

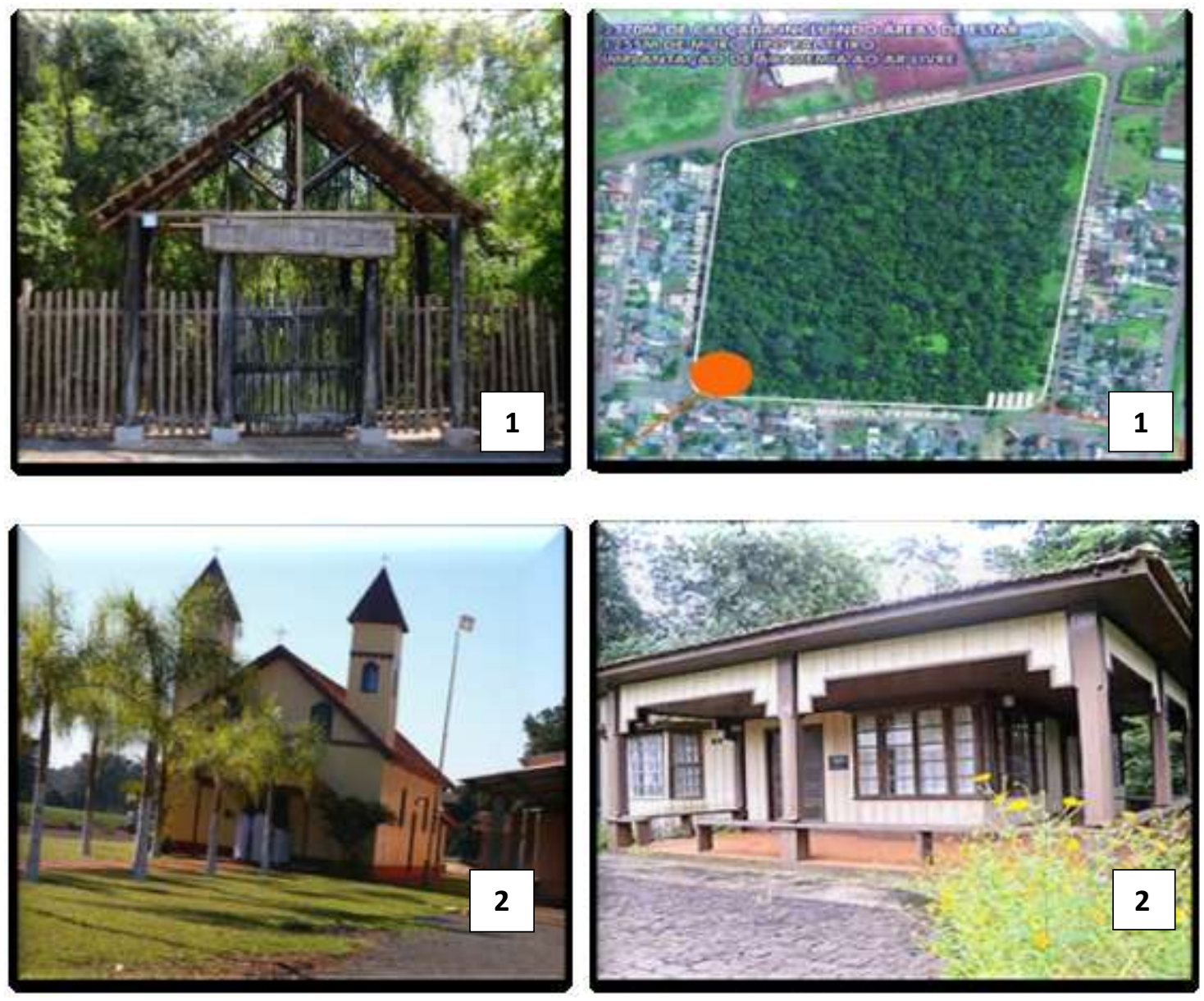

Figura 3. Parque Municipal Peroba Ana Rosa (1) e o Parque Municipal Danziger (2) em Cambé/PR. Fonte: Prefeitura Municipal de Cambé, 2019.

O Parque Municipal Danziger em Cambé, PR possui uma trilha ecológica (Figura 4) que é utilizada por escolas municipais como atividade de educação ambiental. Lemes et al. (2004) destaca que as trilhas devem explorar o raciocínio lógico, incentivar a capacidade de observação e reflexão, além de apresentar conceitos ecológicos e estimular a prática investigatória. As trilhas visam propiciar atividades que revelam os significados e as características do ambiente por meio de uso dos elementos originais, por experiência direta e por meios ilustrativos, encaixando-se como um instrumento básico de Educação Ambiental (Costa et. al. 2012).

Essas trilhas também são uma forma de trazer a necessidade de conservação/preservação dos ambientes naturais, além de poder discutir a importância da percepção ambiental a partir da realização de trilhas interpretativas como meio para uma educação ambiental sensitiva e reflexiva. As trilhas não se limitam-se apenas a observação, mas dos outros sentidos tais como olfato, audição, paladar e tato para que os escolares se conectem com a natureza e que traga para a sua vida a importância da preservação ambiental (DALTO et al., 2020). 

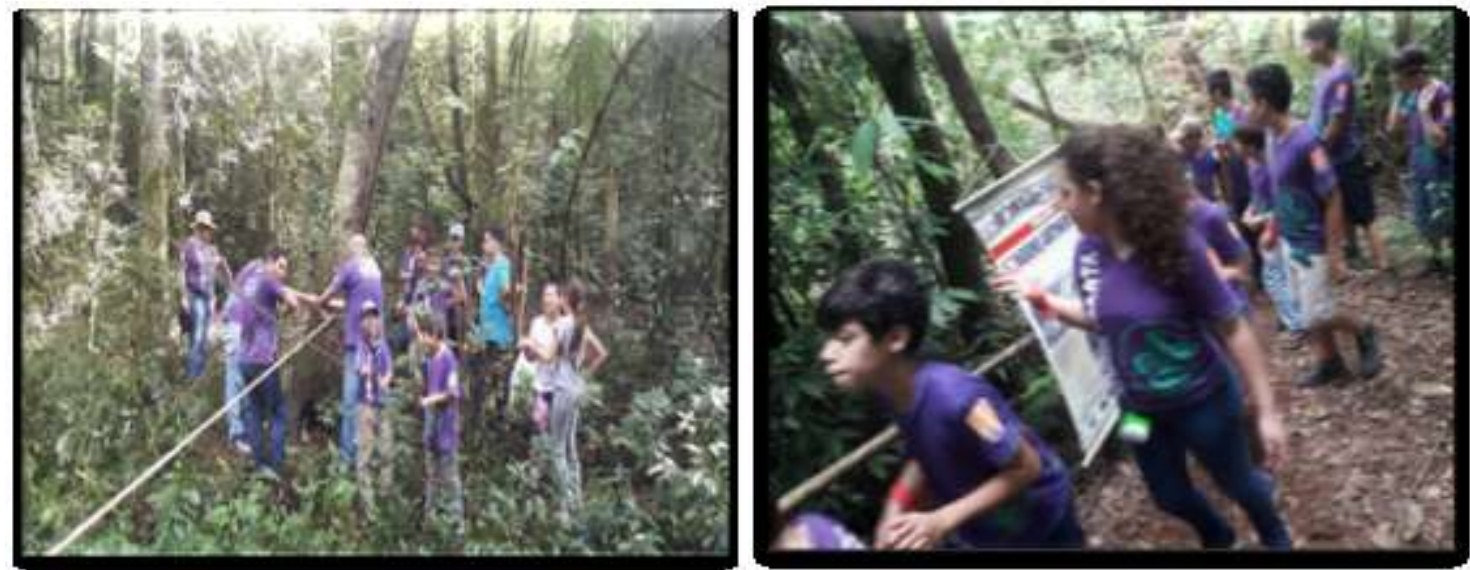

Figura 4. Trilha Ecológica no Parque Municipal Danziger em Cambé/PR. Fonte: Casa Histórica Parque Histórico Danziger Hof.

Segundo Mello (2006), um método importante na Educação Ambiental é transformar a teoria da sala de aula em prática, usando os recursos ecológicos, na qual se destacam as trilhas interpretativas. Estas são utilizadas com frequência em projetos como meio de interpretação ambiental visando não somente a transmissão de conhecimentos, mas também propiciando atividades que analisam os significados dos eventos observados no ambiente bem como as características do mesmo (ZANIN, 2006).

Além de propiciar o contato com a natureza, o descanso, a fruição são também meios eficazes na interação homem/natureza e podem contribuir na formação da consciência ambiental (SIQUEIRA, 2004). Para Dias (1992) e Zanin (2006) as trilhas traduzem para o aluno visitante das áreas naturais, os fatores que estão além das aparências, como as leis naturais, interações, funcionamento, história ou fatos, que, mesmo que evidentes, não são comumente percebidos por quem está caminhando por elas.

A educação ambiental possibilita a formação de valores e atitudes sensíveis à diversidade, à complexidade e à solidariedade diante dos outros seres humanos e da natureza (CARVALHO, 1998). Portanto, é necessário não só oferecer informações, como também propor experiências que reconstruam a conexão entre o ser humano e a natureza (TOMAZELLO; FERREIRA, 2001).

O modo de produção capitalista, caso das cidades brasileiras, faz com que estas cresçam de forma desmesurada e acabem assim por destruir as áreas verdes que entremeavam o ambiente urbano. Segundo Carvalho (2003), o urbanismo no final do século XIX, sob influência europeia, buscou algumas medidas no sentido de abrandar o problema com a implantação de passeios e jardins públicos. Estas ações mitigadoras colocam as áreas verdes como agentes responsáveis pelo resgate do bem-estar da população (FEIBER, 2004).

Assim, o ribeirão Barra Grande foi exposto nas últimas décadas as grandes transformações ao redor de seu leito. Com o crescimento das áreas urbanas grande parte de sua mata foi retirada para que a área urbana pudesse ser expandida e novos empreendimentos imobiliários foram construídos nas suas proximidades (Figura 5). Segundo o plano diretor de Cambé, desde o ano de 1993, cerca de 04 bairros e/ou conjuntos surgiram ao redor do ribeirão, Conjunto Cristal (1993), 
Conjunto Dr. José dos Santos Rocha (1994), Bairro Jardim Europa (2014) e Conjunto Ulysses Guimarães (2016), além de uma estação tratamento de esgoto (ETE - Caçadores) em 1999.

Verificou-se que o ribeirão Barra Grande em Cambé, em algumas das suas áreas visitadas não estão com seu equilíbrio dinâmico preservado e tão pouco mantendo o seu ciclo biológico natural. Sob esse aspecto, percebem-se alterações provocadas pela ação humana. Por consequência, o ciclo ambiental foi alterado e agravantes como poluição, desmatamento, erosão e possíveis problemas de saúde pública, entre outros são constatados.
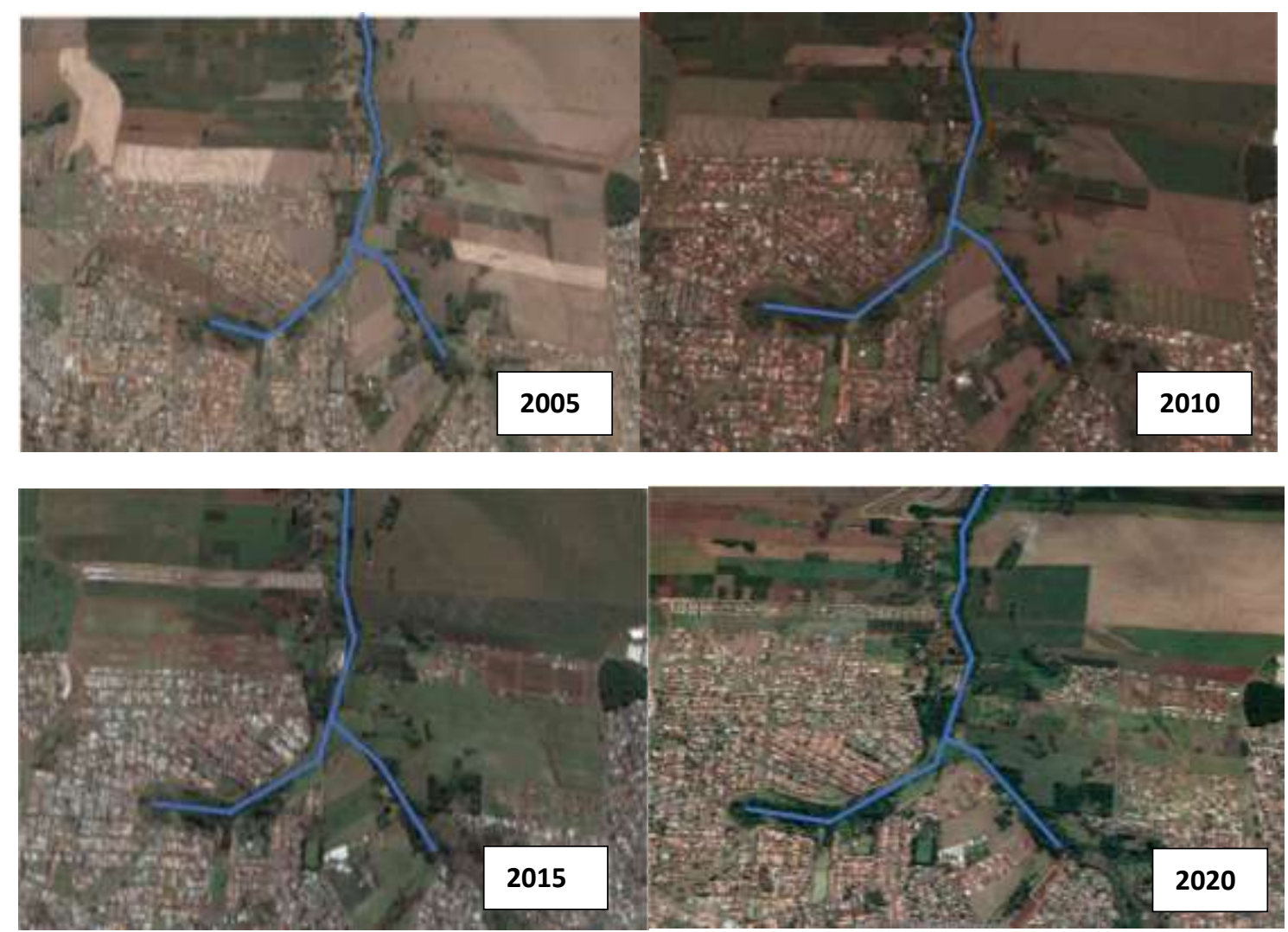

Figura 5. Imagem do ribeirão Barra Grande na cidade de Cambé/PR e a expansão da malha urbana durante 03/2005- 03/2020. Fonte: Google Earth Pro, adaptado pelos autores, 2020.

Com o advento da urbanização e a ausência de um planejamento de responsabilidade sócio/ambiental constataram-se graves problemas de depósitos de dejetos naquele ribeirão como: garrafas pet, latas, lixo orgânico, papéis entre outros resíduos (Figura 6). O lixo causa doenças, e é responsável por uma série de problemas ao planeta causando a poluição da água, a degradação dos mananciais e do solo, prejudicando o meio ambiente sendo responsável pela morte de espécies da fauna e da flora e também trazendo problemas a saúde humana.

O lixo torna-se abrigo e principalmente alimento para o desenvolvimento de várias formas de vida, especialmente de insetos, e animais considerados praga urbana, como ratos, pombos, baratas e moscas, que são transmissores de doenças e de 
agentes que podem causar infecções como vermes, vírus, bactérias e fungos. São muitas as doenças relacionadas ao acúmulo de lixo e a sua falta de tratamento, como, por exemplo, a febre tifoide, peste bubônica, tifo, leptospirose, além de alergias, infecções intestinais, leishmaniose ou calazar, dengue, entre outras (SILVA, 2015).
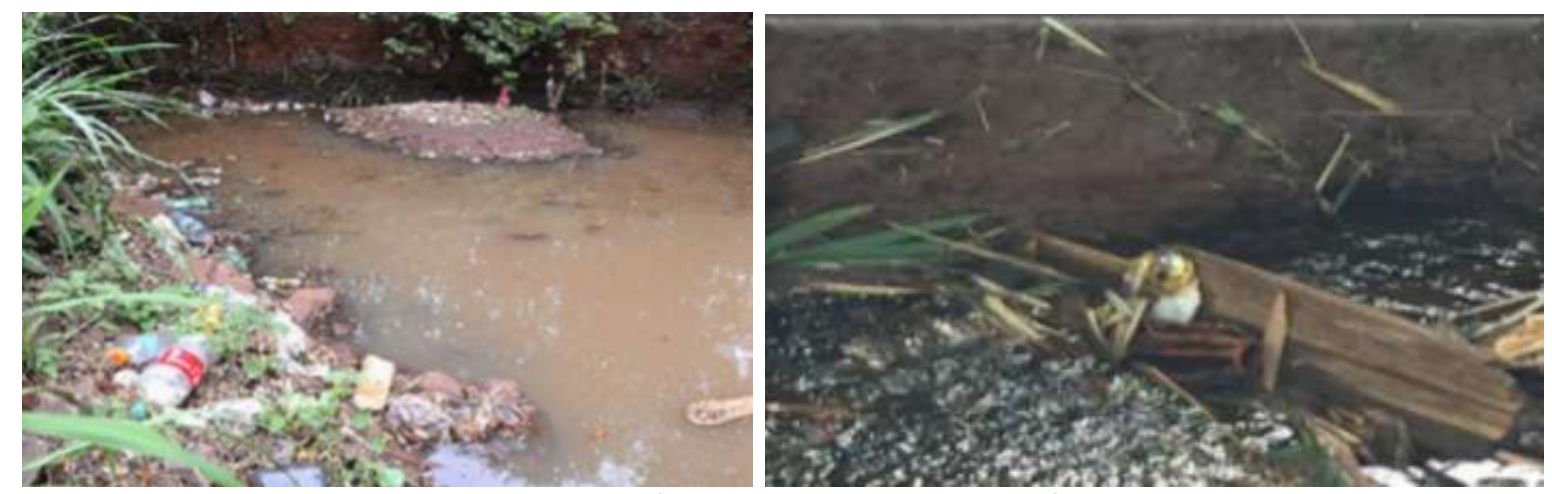

Figura 6. Poluição no ribeirão Barra Grande. Fonte: DALTO et al., 2019.

Neste sentido, verifica-se que o ribeirão está com um processo de mudança de suas características originais, tais fato nos leva a estimar que foram poucas as políticas de intervenção para a proteção e manutenção desta área, pois, somente no ano de 2017 foi aprovado a revisão do plano diretor da cidade com normas para a preservação e/ou conservação ambiental.

Apesar da legislação brasileira ser clara ao considerar criminosa a poluição em diversos meios como a Lei n. 6.938/1981 em seu art. $3^{\circ}$, III, apresenta um conceito genérico de poluição, definindo-a como a "degradação da qualidade ambiental resultante de atividades que direta ou indiretamente prejudiquem a saúde, a segurança e o bem-estar da população; criem condições adversas às atividades sociais e econômicas; afetem desfavoravelmente a biota; afetem as condições estéticas ou sanitárias do meio ambiente e lancem matérias ou energia em desacordo com os padrões ambientais estabelecidos".

No mesmo local, verifica-se que com o advento da retirada de grandes espécies nativas próxima as margens do ribeirão, e a não preservação ambiental de acordo com o Lei $n^{\circ}$ 12.651/2012 (Código Florestal Brasileiro) provocou um grave problema de erosão (Figura 7), causando assim em determinadas épocas do ano, a diminuição ou a exclusão do curso d`água em seu leito em determinadas épocas do ano e extinguindo espécies que antes era seu habitat.

O ser humano como agente modificador da paisagem natural possui responsabilidade pelos impactos causados no espaço ambiental. A questão dos impactos originados pela degradação ambiental é complexa e exige conhecimentos multidisciplinares por parte dos atuantes no manejo do solo ou de outros elementos naturais bem como daqueles que atuam nas políticas públicas (BALSAN, 2006). Esse fenômeno pode ser entendido como uma destruição, deterioração ou desgaste do meio ambiente (LEMOS, 2001).

Um dos grandes responsáveis pela degradação ambiental é o uso intensivo do solo, provocando, segundo Gliessman (2005), a degradação da matéria orgânica e 
compactando-o por meio de maquinário pesado. Outro responsável pela degradação, o uso de agrotóxicos, geram impactos para a saúde humana. Além de poluir o ambiente, esse defensivo agrícola pode causar sérios efeitos na saúde do ser humano que tiver contato com esse tipo de produto (RIGOTTO et al., 2012).
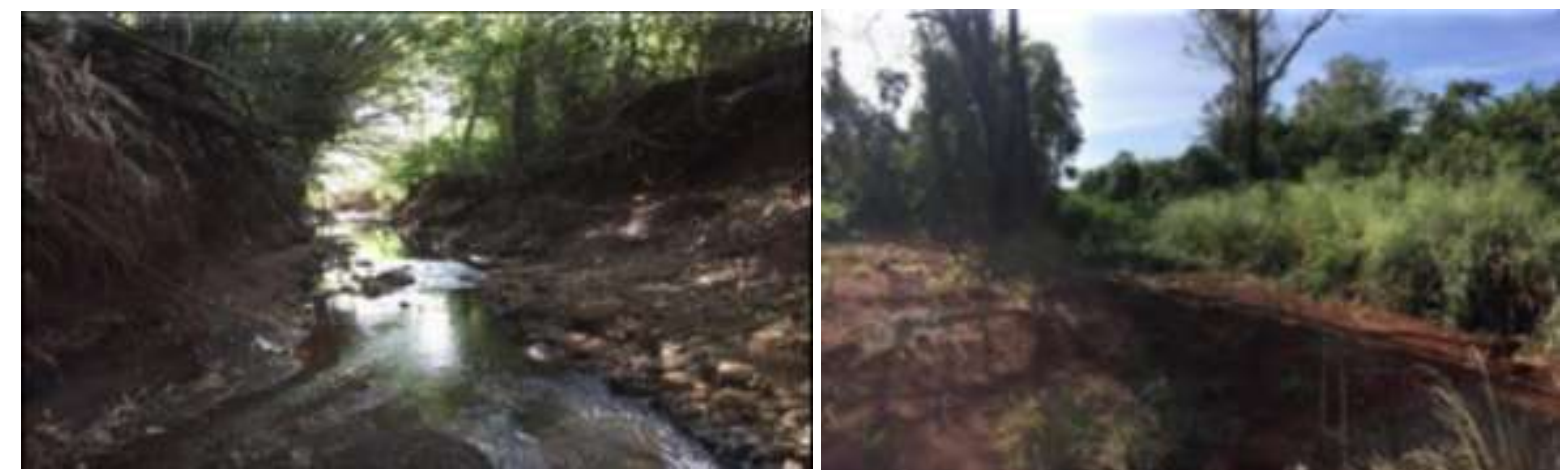

Figura 7. Degradação do ribeirão Barra Grande. Fonte: DALTO et al., 2019

A erosão dos solos em áreas urbanas, geralmente em áreas periféricas com solo descoberto, ocorre com grandes prejuízos materiais e, por vezes, com perdas de vidas humanas resultado do crescimento urbano rápido e desordenado, ocupando o solo sem critérios técnicos que levam em consideração a dinâmica natural do local, além de enchentes, assoreamento de tubulações; solapamento de fundações e pavimentações (GUERRA, 2011).

Além de ser importante preservar os ribeirões e rios da cidade de Cambé para poder trazer uma maior conexão homem-natureza, o município adotou desde 2019, o programa "amigos da praça", que tem como o objetivo de promover a participação de instituições no cuidado com a cidade, permitindo que qualquer pessoa física, entidade da sociedade civil, associação de moradores e pessoa jurídica legalmente constituída possa adotar algum logradouro ou espaço público para realizar a revitalização e a manutenção regular do local com plantio de arvores e flores (PREFEITURA MUNICIPAL DE CAMBÉ, 2020).

O plantio de árvores deve ser planejado, tanto para as áreas verdes (rios, lagos e áreas para serem reflorestadas) quanto para a arborização viária, pois, caso contrário, pode ocorrer uma série de problemas futuros, onde alguns aspectos importantes devem ser considerados na implantação da arborização, tais como os culturais e históricos da localidade ou as necessidades e anseios da comunidade, já que a participação da população é uma condição importante para o sucesso de qualquer projeto de arborização urbana (CEMIG, 2011).

A arborização bem planejada é importante independentemente do porte da cidade, pois, torna-se mais fácil implantar quando se tem um planejamento, caso contrário, passa a ter um caráter de remediação, à medida que tenta se encaixar dentro das condições já existentes e solucionar problemas de toda ordem (PIVETTA; SILVA FILHO, 2002).

A falta de vegetação em ruas e avenidas traz consequências negativas para o meio ambiente urbano como: "alterações do clima local, enchentes, deslizamentos e falta de áreas de lazer para a população" (AMORIM, 2001 p. 38). 
O projeto Amigos da Praça, atua junto à comunidade local, através do (re) plantio de árvores, a floricultura de praças e rotatórias (Figura 8). Como resultado, proporciona uma adoção de medidas para a reabilitação, recuperação ou revitalização das áreas urbanas além de atenuar ruídos, retenção de pó, além de oferecer sombra e a sensação de frescor.
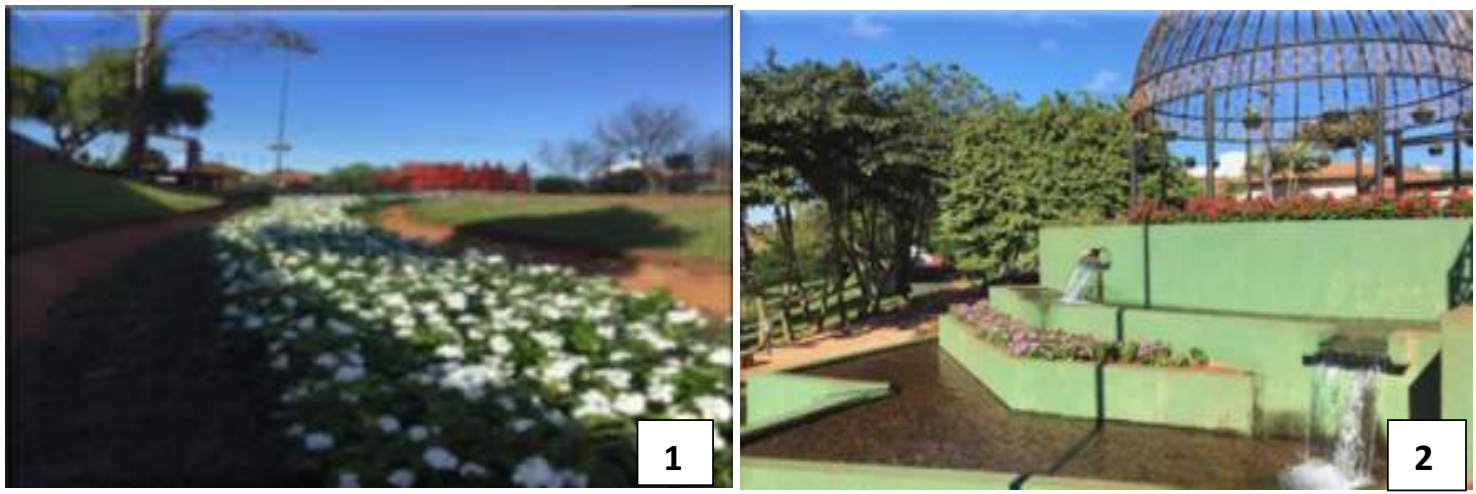

Figura 8. Revitalização de áreas verdes na cidade de Cambé, PR (1. Praça do Sol Nascente, 2. Parque Zezão). Fonte: DALTO et al., 2019.

Desta forma, a cidade apresenta uma melhor qualidade de vida para a sua população, que é estimulada a praticar atividade física ao ar livre e vivenciar um maior convívio com a natureza. No total, hoje são 14 locais que foram recuperados com o plantio de árvores e flores devolvendo a cidade um cenário de maior destaque ambiental para toda região. Foi possível verificar que as áreas verdes assumem um papel muito importante no espaço urbano como a manutenção na qualidade ambiental e na vida da população (PREFEITURA MUNICIPAL DE CAMBÉ, 2020).

As áreas verdes, como parques públicos, as praças, entre outros, podem amenizar os efeitos causados pela densificação dos ambientes urbanos. A massa construída provoca impactos no microclima das regiões que poderão ser amenizados pela presença da vegetação trazendo um maior conforto na vida da população (FEIBER, 2004).

O convívio homem e natureza é possível desde que haja uma maior conscientização (sensibilização) da população a frente das questões de responsabilidade ambiental, como por exemplo, a correta destinação de lixos e dejetos. Por fim, o incentivo do plantio de espécies nativas de árvores em ruas, praças, fundo de vale são essenciais haja vista, que foi preciso uma revisão política principalmente a fim de melhorar a qualidade de vida da população no município (Figura 9). 

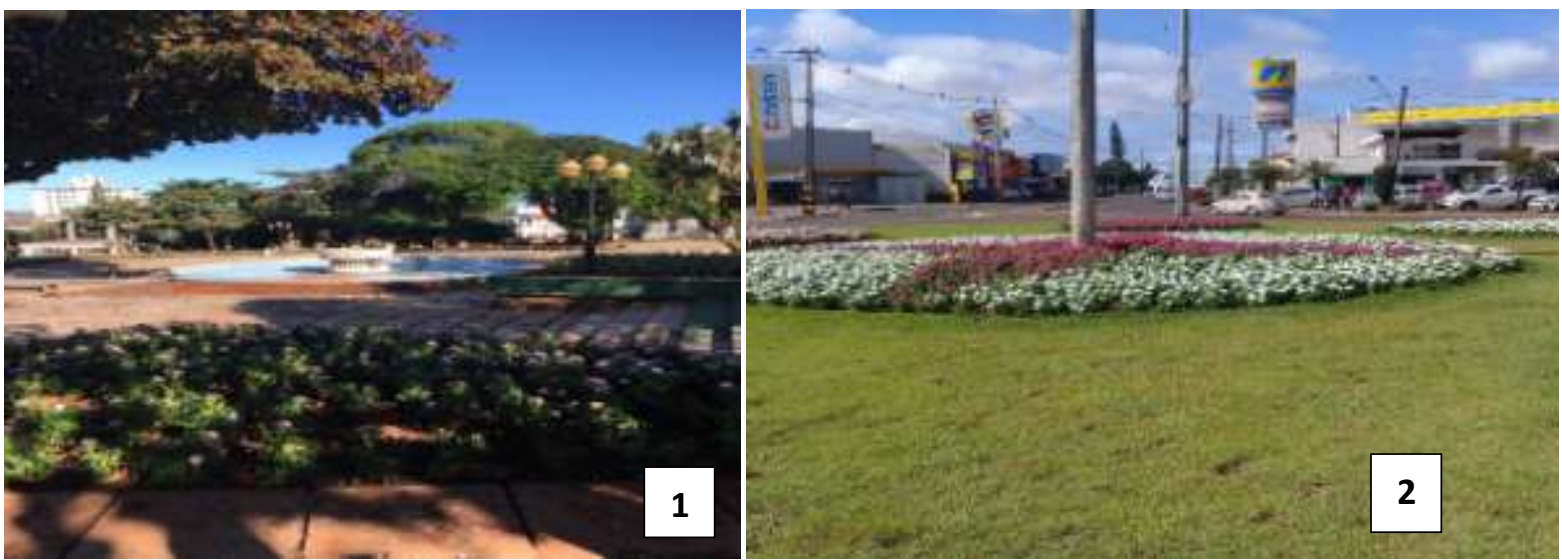

Figura 9. Revitalização de áreas verdes urbanas (1. Praça Getúlio Vargas, 2. Rotatória entre Avenida Inglaterra e a rua Noruega) na cidade de Cambé/PR. Fonte: DALTO et al., 2019.

Assim, Santini (2003) destaca que a utilização de parques e praças pode ser considerada como um índice positivo na qualidade de vida urbana, desde que esses espaços sejam adequados para sua compatibilização como os aspectos cruciais da vida contemporânea e, principalmente, com os lazeres. Também Adams (2002) lembra que na questão urbana e ambiental, a conservação do patrimônio passa a ser considerado o objetivo maior do planejamento, destas áreas, pois os poderes locais são particularmente responsáveis por essa proteção, pois lhes compete a maioria das decisões relativas ao espaço físico das cidades.

\section{CONSIDERAÇÕES FINAIS}

Percebe-se que as áreas verdes no ambiente urbano ou rural são um caminho possível para que homem e natureza tenha uma relação de contato e de sensibilização para a sua conservação. Sendo assim, este trabalho apresentou como resultado que a cidade de Cambé hoje possui 14 "amigos da praça" onde pessoa física ou jurídica pode cuidar de uma área verde pública com a plantação de árvores e flores. Desta forma, homem - natureza são os protagonistas de uma vida saudável e com maior harmonia. Sabe-se que projetos dessa natureza tem a possibilidade de influenciar na qualidade de vida das pessoas através da melhoria da infraestrutura urbana.

É importante pensar e discutir políticas públicas não apenas para a cidade de Cambé, mas para todas as cidades. Há uma grande demanda, entre elas a de realizar um mapeamento urbano com a localização de parques, praças e áreas livres de uso público para que possam auxiliar na identificação de regiões da cidade que necessitam de maiores investimentos em espaços públicos. Dessa forma, é possível fomentar uma redistribuição mais democrática para todas as regiões da cidade.

Verifica-se que os parques municipais são de extrema importância para relacionar a teoria e a prática das salas de aula além, de oportunizar aos professores trabalhar com a sensibilização ambiental e uma educação crítica e sensitiva para a conservação do meio ambiente, além de resguardar a história do município com casas históricas, museu e espécies de árvores em extinção. 
Também verificou-se que o ribeirão Barra Grande está com o processo de mudança em suas características originais, pois a malha habitacional está crescendo desde 1993. Colocando-o em risco com poluição de variados objetos como plástico, papel, pneus, despejo de dejetos entre outros, assim como possível extinção de algumas espécies da fauna e da flora, além de prejudicar a agricultura em toda sua extensão, pois a sua água é utilizada por alguns agricultores para o manuseio de suas plantações.

O estímulo do órgão municipal para que a população adote alguns locais municipais é importante haja vista que a conservação das áreas verdes urbanas é uma estratégica para a própria manutenção da cidade, pois são fundamentais naregulação do microclima, redução de ruídos, filtração do ar, lazer, drenagem das águas pluviais, entre outros, trazendo mais conforto e segurança para toda a população.

O incentivo a conservação e ao plantio de espécies nativas em ribeirões, rios, nascentes e em praças é importante, haja vista que, é preciso uma união política com a sociedade a fim de auxiliar na proteção de espécies nativas que existem nestas localidades, com a finalidade de garantir as futuras gerações o conhecimento das atividades culturais e paisagísticas juntamente com o desenvolvimento das cidades.

\section{REFERÊNCIAS}

ADAMS, B. Preservação urbana: gestão e resgate de uma história - Florianópolis: Ed. Da UFSC, 2002. 192p.

AMORIM, M. C. da C. T. Caracterização das áreas verdes em Presidente Prudente/SP. In: SPOSITO, Maria Encarnação Beltrão (org). Textos e contextos para a leitura geográfica de uma cidade média. Presidente Prudente: [s. n.], 2001 p. 3752.

BALSAN, R. Impactos Decorrentes da Modernização da Agricultura Brasileira. CAMBÉ, Prefeitura Municipal de. História de Cambé. 2021. Disponível em: http://www.cambe.pr.gov.br/site/index.php/cambe/\#: :text=0\%20top\%C3\%B4nimo\% 20Camb\%C3\%A9\%20origina\%2Dse, derivando\%20o\%20nome\%20de\%20Camb\%C 3\%A9\%22. Acesso em: 12 jan. 2022.

CAMPO TERRITÓRIO: Revista de Geografia Agrária, Francisco Beltrão, v. 1, n. 2, p. 123-151, 2006.

BUCCHERI-FILHO, A. T.; TONETTI, E. L. Qualidade ambiental nas paisagens urbanizadas. Revista Geografar. Curitiba: UFPR, v.6, n.1, p.23-54, jun./2011.

CALDANA, N. F. S. et al. Ocorrências de Alagamentos, Enxurradas e Inundações e a Variabilidade Pluviométrica da Bacia do Rio Iguaçu. Revista Brasileira de Climatologia, v. 23, p. 343-355, 2018.

CARVALHO, I. C. M. Em direção ao mundo da vida: interdisciplinaridade e educação ambiental. IPE - Instituto de Pesquisas Ecológicas, Brasília, Brasil: 102 p. 1998.

CARVALHO, P. F. Repensando as áreas verdes urbanas. Rio Claro: Unesp, Território e Cidadania, 2003.

CAVALHEIRO, F.; DEL PICCHIA, P. C. D. Áreas Verdes: Conceitos, Objetivos e Diretrizes para o Planejamento. In: CONGRESSO BRASILEIRO SOBRE 
ARBORIZAÇÃO URBANA,1., ENCONTRO NACIONAL SOBRE ARBORIZAÇÃO URBANA, 4.,1992. Vitória/ES. Anais...Vitória/ ES, 1992. p. 29-38.

CEMIG, Companhia Energética de Minas Gerais. Manual de arborização. Belo Horizonte: Cemig / Fundação Biodiversitas, 2011.

COSTA, M. M. S. et al. Proposta de trilha ecológica como atrativo ecoturístico na área de proteção ambiental da barra do Rio Mamanguape - PB. Revista Turismo: estudos e práticas, Mossoró, v.1, p.104-117, 2012.COSTA, R. G. S.; COLESANTI, M. M. A Contribuição da Percepção Ambiental nos Estudos das Áreas Verdes.

$R A^{\prime} E G A$. Curitiba: UFPR, v.22, p. 238-251, 2011.

DALTO, C. C.; COLTRO, B.; ARAUJO, T.; MOURA, J. D. PETRILHAS: vivência e interpretação da natureza. ENAPET, 2020. DIAS, G. F. Educação Ambiental:

princípios e práticas. p. 75 - 76, São Paulo: Gaia, 1992.

FEIBER, S. D. Área verdes urbanas imagem e uso - o caso do Passeio Público em Curitiba - PR. RA'E GA. Universidade Federal do Paraná (UFPR), Curitiba, n. 8, p. 93-105, 2004.

GLIESSMAN, S. R. Agroecologia: processos ecológicos em agricultura sustentável. $3^{a}$ ed. Porto Alegre: Editora da UFRGS, 2005.

GUERRA, A. J. T. Geomorfologia urbana. 1. Ed. Editora Bertrand, Brasil, p. 280, 2011.

GUZZO, P. Estudos dos espaços livres de uso público e da cobertura vegetal em área urbana da cidade de Ribeirão Preto-SP. Dissertação (Mestrado em

Geociências). Instituto de Geociências e Ciências Exatas, Universidade Estadual

Paulista, Rio Claro. 1999. 106f.

IAPAR. Instituto Agronômico do Paraná. Dados Diários de Londrina - Precipitação e Temperatura. 2019. Disponível em:

http://www.iapar.br/modules/conteudo/conteudo.php?conteudo=2612 Acesso em: 12 de janeiro de 2022.

IBGE. (Fundação Instituto Brasileiro de Geografia e Estatística), CENSO DEMOGRÁFICO: BRASIL, 2010. Rio de Janeiro: IBGE, 2020.

IBGE, Fundação Instituto Brasileiro Geografia e Estatística. Território e Ambiente, 2019. Disponível em: https://cidades.ibge.gov.br/brasil/pr/cambe/panorama. Acesso em: 01 mar. 2021.

IBGE. (Fundação Instituto Brasileiro de Geografia e Estatística), Censo

Demográfico: Brasil, 2021. Rio de Janeiro: IBGE, 2022.

IBGE, Instituto Brasileiro de Geografia e Estastísticas. IBGE Cidades. 2022.

Disponível em: https://cidades.ibge.gov.br/brasil/pr/cambe/historico. Acesso em: 12 jan. 2022.

KAMP, I. V; LEIDELMEIJER, G. M.; HOLLANDER, A. Urban environmental quality and human well-being: towards a conceptual framework and demarcation of concepts; a literature study. Landescape and Urban Planning, v.65, n.1, p. 5-18, 2003.

LEMES, E. O. A.; RODRIGUES, M.; MOURA. Criação de três trilhas interpretativas como estratégia em um programa de interpretação ambiental do Parque Estadual do Itacolomi. Relatório do Projeto: UFOP: Ouro Preto. 2004.

LEMOS, J. J. S. Níveis de Degradação no Nordeste Brasileiro. Revista Econômica do Nordeste, Fortaleza, v.32, n. 3, p. 406-429, 2001. 
LIMA, A. M. L. P.; et. al. Problemas de Utilização na Conceituação de termos como Espaços Livres, Áreas Verdes e Correlatos. In: CONGRESSO BRASILEIRO SOBRE ARBORIZAÇÃO URBANA, 2., 1994, São Luis, MA: Anais... 1994. p. 539-553.

LOMBARDO, M. A. Ilha de calor nas metrópoles. São Paulo: Hucitec, 1985.

LONDE, P. R.; MENDES, P. C. A influência das áreas verdes na qualidade de vida urbana. Revista Brasileira de Geografia Médica e da Saúde. Uberlândia, v. 18, n. 10, p. 264-272, jun. 2014.

MAZZEI, K; COLESANTI, M. T. M.; SANTOS, D. G. Áreas Verdes Urbanas, Espaços Livres para o Lazer. Revista Sociedade e Natureza, Uberlândia, v.19, n.1, p. 33-43, 2007.

MELLO, N. A. Práticas de Educação Ambiental em Trilhas Ecológicas. Publicação de divulgação do Curso de Ciências Biológicas. UNISC. Santa Cruz do Sul. 2006. NOGUEIRA. R. Geografia em múltiplas escalas do local ao global: o município de Cambé. Universidade Estadual de Londrina (UEL), v. 2, Londrina, 2008.

$\mathrm{NUCCl}$, J. C. Qualidade Ambiental e adensamento urbano: um estudo de ecologia e planejamento da paisagem aplicada ao Distrito de Santa Cecília- SP. 150p. 2 ed. Curitiba, 2008.

PADUA, S. M.; TABANEZ, M. F. Educação Ambiental Caminhos Trilhados no Brasil. v. 5, p. 37-44, IPÊ, 1997. São Paulo.

PIVETTA, K. F. L.; SILVA FILHO, D. F.; Arborização Urbana. Boletim Acadêmico. Jaboticabal: UNESP, 2002.

PREFEITURA DE CAMBÉ. Dados Gerais de Cambé. Disponível em:

http://www.cambe.pr.gov.br/site/cambe/dadosgeraiscambe.html Acesso em: 07 de abril de 2020.

QUEIROZ. D. A. H. O. Avaliação da qualidade das áreas verdes urbanas: uma abordagem com base nas suas funções. Tese (Doutorado em Geografia)

Universidade Estadual de Ponta Grossa (UEPG), Programa de Pós-Graduação em Geografia, 2018. 212 f.

RIGOTTO, R. M.; CARNEIRO, F. F.; MARINHO, A. M. C. P.; ROCHA, M. M.;

FERREIRA, M. J. M.; PESSOA, V. M.; TEIXEIRA, A. C. de A.; SILVA, M. de L. V. da; BRAGA, L. de Q. V.; TEIXEIRA, M. M. O verde da economia no campo: desafios à pesquisa e às políticas públicas para a promoção da saúde no avanço da modernização agrícola. Revista Ciência \& Saúde Coletiva. Rio de Janeiro, v. 17, n. 6, p. 1533-1542, 2012.

SANTINI, R. de C. G. Dimensões do lazer e da recreação - questões espaciais, sociais e psicológicas. São Paulo: Angelotti, 2003.

SANTOS, M. C. dos; FLORES, M. D.; ZANIN, E. M. Educação ambiental por meio de trilhas ecológicas interpretativas com alunos NEES. Remoa, Santa Maria, v. 5, n. 5, p. 982-992, 2012. Disponível em:

https://periodicos.ufsm.br/remoa/article/view/4222/2769. Acesso em: 01 mar. 2021. SILVA, G. M. F. et al. O Jornal Como Fonte de Informações sobre Precipitação de Granizo no Estado do Paraná. Revista GeoNorte, Manaus, v.1, p. 1079-1090, 2012. SILVA. E.; Educação ambiental: lixo urbano de problema a possibilidades. Universidade Federal do Paraná (UFPR), Setor Litoral. Curso de Especialização Educação em Direitos Humanos. Paranaguá, p. 10 -15, 2015.

SIQUEIRA, L. F. Trilhas interpretativas: Uma vertente responsável do (eco) turismo. Caderno Virtual de turismo, $\mathrm{n}^{\circ}$ 14, 2004. Disponível em: 
http://www.ivtrj.net/caderno/anteriores/14/siqueira/siqueira.pdf. Acesso em 12/06/2011. Acesso em: 01 de outubro de 2020.

TOMAZELLO, M. G. C.; FERREIRA, T. R. C. Educação Ambiental: que critérios adotar para avaliar a adequação pedagógica de seus projetos. Ciência \& Educação. Piracicaba, v.7, n.2, 2001.

ZANIN, E. M. Projeto trilhas interpretativas - a extensão, o ensino e a pesquisa integrados à conservação ambiental e à educação. Vivências. 1(1):26-35, 2006.

Recebido em 22/12/2021

Aceito em 18/01/2022 